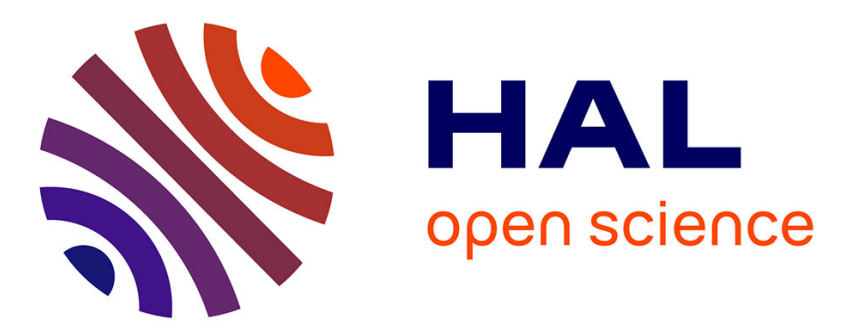

\title{
A Proposal of Manufacturing Execution System Integration in Design for Additive Manufacturing
}

Gianluca D'antonio, Frédéric Segonds, Joel Sauza Bedolla, Paolo Chiabert, Nabil Anwer

\section{- To cite this version:}

Gianluca D'antonio, Frédéric Segonds, Joel Sauza Bedolla, Paolo Chiabert, Nabil Anwer. A Proposal of Manufacturing Execution System Integration in Design for Additive Manufacturing. 12th IFIP International Conference on Product Lifecycle Management (PLM), Oct 2015, Doha, Qatar. pp.761770, 10.1007/978-3-319-33111-9_69 . hal-01377504

\section{HAL Id: hal-01377504 \\ https://inria.hal.science/hal-01377504}

Submitted on 7 Oct 2016

HAL is a multi-disciplinary open access archive for the deposit and dissemination of scientific research documents, whether they are published or not. The documents may come from teaching and research institutions in France or abroad, or from public or private research centers.
L'archive ouverte pluridisciplinaire HAL, est destinée au dépôt et à la diffusion de documents scientifiques de niveau recherche, publiés ou non, émanant des établissements d'enseignement et de recherche français ou étrangers, des laboratoires publics ou privés.

\section{(c)(1)}

Distributed under a Creative Commons Attribution| 4.0 International License 


\title{
A proposal of Manufacturing Execution System integration in Design for Additive Manufacturing
}

\author{
Gianluca D’Antonioํㅜ Frédéric Segonds ${ }^{2}$, Joel Sauza Bedolla ${ }^{1}$, Paolo Chiabert ${ }^{1}$, \\ Nabil Anwer ${ }^{3}$, \\ ${ }^{1}$ Politecnico di Torino, corso Duca degli Abruzzi 24, 10129, Torino, Italy \\ \{gianluca.dantonio, joel.sauza, paolo.chiabert\}@ polito.it \\ ${ }^{2}$ Ecole Nationale Supérieure d'Arts et Métiers, 151 bd. de l'Hôpital, 75013, Paris, France \\ frederic.segonds@ensam.eu \\ ${ }^{2}$ Ecole Normale Supérieure de Cachan, 61 avenue du Président Wilson, 94235, Cachan \\ Cedex, France \\ nabil.anwer@lurpa.ens-cachan.fr
}

\begin{abstract}
The deployment of Additive Manufacturing processes had a rapid and broad increase in the last years, and the same trend is expected to hold in the near future. A way to better exploit the advantages of such technology is the use of Design for Additive Manufacturing (DFAM), a set of methods and tools helpful to design a product and its manufacturing process taking into account AM specificities from the early design stages. However, until now DFAM has not received feedback information from the shop-floor additive machines. To overcome this information lack, we present in this paper an integration between DFAM and a Manufacturing Execution System (MES), an information framework able to real-time acquire, analyze and synthesize process and product data. The MES-DFAM cooperation allows to improve product quality and process performance, and to better deal with possible criticalities, both in the prototyping and in the mass production phases.
\end{abstract}

Keywords: Design for Additive Manufacturing (DFAM), Manufacturing Execution System (MES), Additive Manufacturing, Information systems, Monitoring systems.

\section{Introduction}

According to the ASTM standard [1], Additive Manufacturing (AM) is defined as "the process of joining materials to make objects from 3D model data, usually layer upon layer, as opposed to subtractive manufacturing methodologies, such as traditional machining". Several synonyms are also defined for AM: additive fabrication, additive processes, additive techniques, additive layer manufacturing, layered manufacturing, rapid manufacturing and freeform fabrication. The first step of an additive fabrication process is to decompose the model data of a part into a set of 
2D cross sections. Then, the AM machine adds material layer by layer to produce the physical object.

Appropriate tools are necessary to fully exploit this technology and its advantages. Currently, there is a lack of appropriate information tools to support and promote this innovative fabrication process. The absence of design instruments is particularly noticeable [2]. Thus, the aim of this paper is to provide a framework for the deployment of new information tools for additive fabrication and their integration with each other to support the design.

Actually, few work has been done in the field of the integration between Product Lifecycle Management (PLM) and Manufacturing Execution Systems (MES) for traditional manufacturing processes. A first attempt has been done by Ben Khedher et al. [3], who proposed a model for data exchange between PLM and MES. In D'Antonio et al. [4] an application for this cooperation has been proposed in the field of aeronautic industry. A schematic of the information exchange between the two information systems is shown in Fig. 1. PLM-MES integration is helpful because it allows to compare the product and process «As-Is» conditions with respect to the «To-Be» states. This cooperation can lead to the creation of a knowledge-based system covering the whole product lifecycle and makes feasible a quick feedback information mechanism, which is critical for the implementation of continuous improvement practices. The improved data exchange can allow to plan innovative strategies and make decisions for better and faster reactions to market changes, and to enhance the competitiveness of a company.

Up-to-date, no applications of MES in the field of additive manufacturing exist in literature. In this work we will provide a framework for the deployment of such information systems in $\mathrm{AM}$ and to integrate it with Design for Additive Manufacturing (DFAM), a set of methods and tools helpful to design a product and its manufacturing process taking into account AM specificities from the early design stages. In section 2 we briefly review additive manufacturing technologies and introduce DFAM. In section 3 we introduce MES and explain its possible deployment in additive manufacturing. In section 4 the MES-DFAM integration and its advantages are treated; finally, some conclusive remarks and hints for future work are provided.

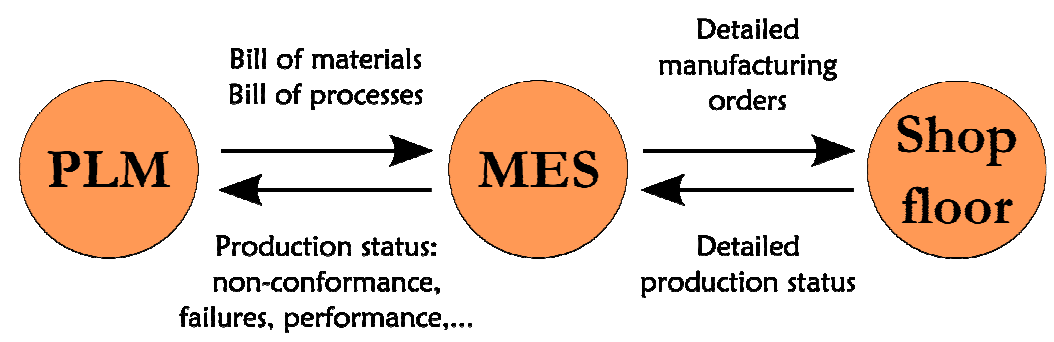

Fig. 1. Schematic of information exchange between PLM, MES and the information systems deployed at the shop floor. 


\section{Additive manufacturing}

\subsection{AM technologies}

Today, several AM technologies are available; the choice of a particular fabrication process is strictly tied to the deployed material: polymers, metals, ceramics and organic materials are among the main ones [5]. Material extrusion is among the most deployed methodologies: a thermoplastic material is heated over its glass transition temperature and extruded through a nozzle in a controlled manner. The extruded material is used to print 2D sections successively, one on-top of another, until the object is complete. Due to their relatively low glass transition temperatures, ABS and PLA are the mostly deployed thermoplastic polymers in material extrusion $[6,7]$. Metal AM is mainly based on powder: materials currently used include steels, pure titanium and titanium alloys, aluminum casting alloys, nickel based alloys, gold and silver. The list of metals and alloys deployable in AM grows as new technologies emerge [8]. However, currently no process is able to create net shape parts, and a post-processing operation is necessary (for example, to remove supports or to finish the surface). Thus, a stand-alone AM implementation is not feasible, and the integration among production processes is necessary [6].

The first advantage of AM processes is design freedom: possibilities in shape complexity and custom geometry are extraordinary, compared to traditional manufacturing technologies [9]. Furthermore, material waste is reduced, time-tomarket is shortened and a just-in-time production approach is feasible [8]. Moreover, in traditional processes different stages take place at different locations, while this does not occur in additive fabrication: hence, transportation problems, cost and energy consumption are reduced [9].

The applications of additive processes are increasing as new materials are available. Currently, AM technology is deployed in aerospace, automotive and biomedical devices manufacturing. The highly customization level allows to profitably deploy freeform fabrication in personalized products and in the production of small lots [6]. Beyond end-user products, an indirect usage of AM is also feasible, for example to develop and produce tools for conventional machines [9].

The AM market is significantly growing in every manufacturing sector: in 2012, the global additive manufacturing market was $\$ 1.8$ billion; due to the continuous improvement in the performance and cost reduction of manufacturing systems, and the development of new materials, this market is expected to grow at a $13.5 \%$ rate, reaching $\$ 3.5$ billion by $2017[10,11]$.

\subsection{AM methodologies}

Currently, research in AM is focused on developing new materials, software and processes; little investigation is performed on the methods for designers. Nevertheless, the design has a remarkable impact on the downstream phases, e.g. production, distribution, utilization and disposal. The DFAM methodologies are now a major issue to exploit in an appropriate manner the potential of AM Technologies for product development [12]. Furthermore, digital fabrication and on-demand 
production dramatically changed the manufacturing paradigms. AM allows to produce huge quantities as well as small volumes of a product, with little or no stock; furthermore, a customer can look for a product in a digital catalogue, customize it and send the resulting file to a small firm to fabricate it [5]. To manufacture high-quality products, the properties of the material must be well-known; however, these properties can strongly vary according to the production parameters, such as the orientation of the part in the 3D printer, the build speed and the tool path. Thus, the deployment of a consistent and structured design approach is mandatory. In traditional processes, Design for Manufacturing (DFM) practice is deployed to eliminate production issues, and minimize manufacturing, assembly and logistics costs [13]. However, additive processes have different constraints and DFM cannot be deployed as it is; it must be re-thought to take into account the unique capabilities of $\mathrm{AM}$, in order to fully exploit the advantages of such technology and consider its limits from the early design stage [14]: in particular, new design tools are necessary to define and explore product shape and properties, new materials, new efficient manufacturing processes, and to assess lifecycle costs [15].

Design for Additive Manufacturing is a set of methods and tools helpful to design a product and its manufacturing process taking into account AM specificities from the early design stages: DFAM allows to determine an optimized process planning from the functional specifications [16]. Rosen [17] defines DFAM as the synthesis of shapes, sizes, geometric mesostructures, and material compositions and microstructures to best utilize manufacturing process capabilities to achieve desired performance and other life-cycle objectives. He also defines the DFAM structure shown in Fig. 2. Design is represented by the right-left flow: functional requirements are transformed into properties and an appropriate geometry; a process planning is performed to formulate a potential manufacturing process. On the left-right flow, the designed object and its fabrication are simulated to determine how well the original requirements are satisfied.

Another structure for DFAM is formulated by Ponche et al. [16] (Fig. 3): their methodology is organized in three steps: determination of part orientation into the machine; topological optimization of the part; optimization of the manufacturing paths. This methodology allows to take into account the characteristics and constraints of the chosen AM process from the early stage of design.

In the next section, the functionalities of a MES and their possible cooperation with DFAM will be discussed.

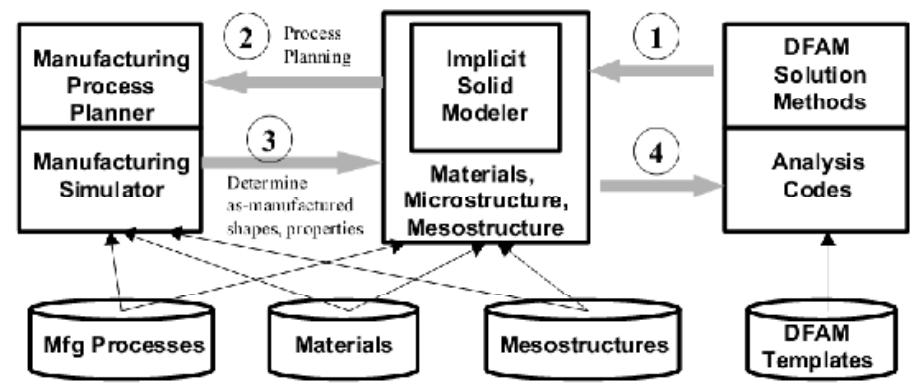

Fig. 2. Design for DFAM methodology extracted by Rosen [17]. 


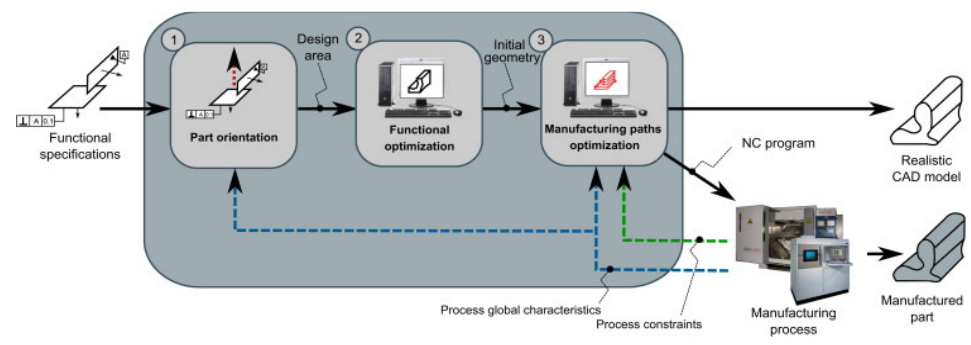

Fig. 3. Design for DFAM methodology extracted from Ponche et al. [16].

\section{Manufacturing Execution Systems}

Manufacturing Execution Systems are IT tools commonly deployed in companies involved in traditional manufacturing. A MES enables information exchange between the organizational level, commonly supported by an ERP, and the control systems for the shop-floor, usually consisting in several, different, very customized software applications [18]. A MES has two principal purposes. First, the system has to identify the optimal sequence planning taking into account the constraints of the process, such as processing and setup times, and workstations capacity, considering the requirements and the necessities given by the organizational level. The system also has to manage and allocate resources such as the staff and the material necessary for the manufacturing process. There exist a large variety of commercial software able to deal with this kind of tasks: among them, the most popular are designed by Siemens, Dassault Systemes, General Electric, Rockwell Automation, ABB.

The second aim of a MES is to manage the bottom-up data flow: recently, the development of low-cost, small, easily available sensors led to a great diffusion of monitoring systems to assess product quality and process performance, and to support the improvement of production process. The role of the MES is to collect the shopfloor information, analyze it through proper mathematical techniques, and provide an exhaustive picture of the current state of the process. Possibly, the analysis should be performed in real-time, in order to make decisions to control the process with the necessary rapidity. Examples of real-time monitoring systems integrated in MES are provided in [19-21].

MES for Additive Manufacturing. At the state of the art, there is no application of MES in the field of additive fabrication. In literature there exist some predictive models based on the values of machine parameters. In Vijayaraghavan et al. [22] a model to predict wear strength of a part is provided, based on layer thickness, orientation, air gap, raster angle and width. Byun and Lee [23] developed a decision making strategy for part orientation based on surface quality, building time and part cost. Sood et al. [24, 25] use air gap, raster angle and raster width to predict the wear rate and the compressive resistance of a part. However, the unpredictability of possible anomalies and failures necessitates the use of sensor-based monitoring systems. Rao et al. [7] measured vibrations and temperatures to optimize process conditions, in order to obtain the best surface roughness and to real-time detect 
possible drifts. In [26] a set of accelerometers is used to trace in real-time variations in process dynamics and to early detect possible anomalies. Faes et al. [27] deploy an optical sensor to measure layer width and height and to control the geometrical error in the $z$ direction (perpendicular to slicing direction, traditionally vertical).

In the cited examples, the monitoring systems are only used for real-time adjustment of the fabrication process to obtain the best possible quality of the object currently in production. Nevertheless, shop-floor data contain a huge quantity of information useful for different purposes. This information has to be properly extracted and dispatched. For example, in traditional manufacturing an integration between PLM and MES is recommended: in case a criticality arises, the cooperation between the two systems allows to react quicker and with better results [4]. Also in the field of additive manufacturing proper information tools must be deployed to fully exploit this technology. In this work, we focus on the integration between a MES and a DFAM; in the next section, a framework for this cooperation will be exhaustively discussed.

\section{Integration between MES and DFAM}

The analysis of data collected by a sensor-based monitoring system is a task that has to be performed by a MES. Several typologies of algorithms can be used, according to the deployed kind of sensors and to the time-scale of interest. Sensorfusion methodologies can be used to correlate the values for different variables with the state of the machine and the quality of the produced object. Possibly, the analysis should be performed in real-time, to improve the reactiveness of the production system.

The results of the elaboration can be used with different purposes. First, they can be deployed to adapt machine parameters for drifts or errors compensation: automatic correction strategies can be developed, as well as instruments to support the awareness of operators decisions. Second, a synthesis of the collected data that highlights the reasons for which criticalities occurred or predicts them in advance can be provided to the organizational level of the company, allowing it to plan actions that can enhance the performance of the manufacturing process.

Furthermore, a very useful deployment of MES output can be made by the design tools. In the field of additive manufacturing, DFAM can fruitfully deploy the data elaboration performed by the MES. This allows the design to have a continuous feedback concerning what occurs on the shop-floor. In this way, the design of a product and the related fabrication process can be continuously adapted and improved. A schematic of a framework for information exchange between the two information systems is shown in Fig. 4.

MES-DFAM integration allows to extend the DFAM model proposed by Ponche et al. [16] (shown in Fig. 3). The model consists in three tasks and is able to optimize the design of a product taking into account the capabilities and the constraints of the process that will be used for its fabrication. In our view, MES support can be useful to improve the result of all the three tasks performed by the DFAM. 


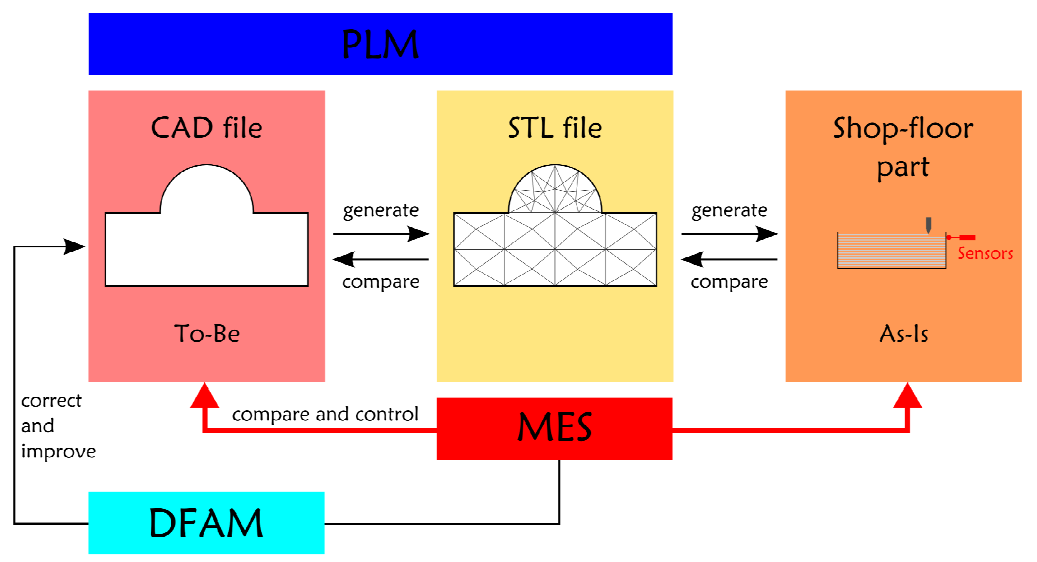

Fig. 4. Proposed methodology for the integration between MES and DFAM.

First, part orientation has a strong impact on the quality of the finished part. Decision support tools have been developed to identify the part orientation that results in the best roughness and accuracy of the produced object. However, such tools are based on predictions and simulations of process behavior. A feedback information from a set of sensors able to evaluate the quality of the physical part would be useful to validate the predictions and, in case of mismatching, to correct the model and the orientation of the part into the machine. Second, the shop-floor information can also be used for further adjustments of the part geometry. In case the quality or the precision of specific features is not satisfactory, the shape of the object and the material distribution can be revised more quickly. The third task included in the DFAM methodology is the optimization of manufacturing paths and machine parameters. A feedback information from the shop-floor is useful because even minute uncontrolled variations can lead to strong differences in the quality of the fabricated part. Several variables can affect the production process, concerning the deposition (angle of the nozzle with respect to the beam, velocity at which the material is fed) and the material (melt pool geometry, temperature, deposition height); furthermore, the output quality is also correlated to the state of the deposition chamber (such as temperature, humidity or oxygen concentration) [28]. All these parameters interact with each other. It is not trivial to ensure the quality of a produced part by controlling only a few variables, but further adjustments to the machine parameters can be necessary according to the real operating conditions. Such adjustments can be taken according to the measurements performed by the sensors, and a MES-DFAM integration allows to quicker take decisions and actions to improve output quality.

Our proposal for MES-DFAM integration also allows to extend the model proposed by Rosen et al. [17] (see Fig. 2): after planning a manufacturing process, they perform simulations to check whether the design process results in producing an object in compliance with the specifications. Such simulations can be supported by the MES feedback, that allows to continuously validate the process and its model. In 
case an issue arises, alarms may be generated, or strategies for self-adaptation or selfcompensation can be undertaken. Furthermore, functionalities to early detect possible decays of the process over a longer time scale can be implemented.

Expected advantages. Currently, the most important challenges in additive manufacturing are poor part accuracy and lack of process repeatability [7]. This is due to the complex relationships among variables which are, in many cases, still unknown. Furthermore, the assessment of the current fabrication process state is not sufficient to understand the whole additive phenomena: the history of variables such as the temperature distribution in the build chamber must be traced. The deployment of an heterogeneous sensor-based monitoring system allows to extract new knowledge which, in turn, should be used to improve the predictive ability of process models. Enriched models can lead to better product design and to a finest process tuning. As a consequence, improved quality of the output can be reached (e.g. lower surface roughness and stair-stepping effect, or improved stress resistance). To improve geometric quality, shape deviations should also be considered [29, 30]. Therefore, the product shape must be changed by compensating the geometric deviations [31, 32]. An improved control can also enhance process repeatability, and tighter tolerances can be satisfied.

Furthermore, a direct communication between MES and DFAM allows to reduce the ramp-up phase of a new product: machine parameters can be tuned in real-time, and the acquired experience can be used for further product developments. This, in turn, allows to decrease material and energy waste for unsatisfactory productions, leading to cost reductions and improved sustainability. Wastes can also be reduced by a continuous monitoring of the part during the fabrication process: if the sensors detect poor quality of the object and improvements are not possible, the process may be stopped to avoid useless operations and material consumption.

MES-DFAM integration can also be helpful in testing new materials or alloys: the sensors-based system can collect information about the behavior of the process and the quality of the product. The acquired data may validate the expected performance, or provide hints for further adjustments or improvements.

\section{Conclusions and future work}

In this paper, a theoretical framework for the integration between MES and DFAM has been developed. In section 4 the possible advantages due to such integration have been discussed. However, despite the numerous advantages shown, the deployment of monitoring systems is currently restricted by the lack of proper smart sensors. This is mainly due to two factors. The first one is a lack of access to the build chamber. The second is the need for intensive computing power: due to the very small time scale at which additive phenomena occur, fast and reliable in-situ measurements must be performed. Furthermore, data elaboration must be fast in order to online control the process and attempt to repair possible defects.

The systems integration proposed in this paper seems to be promising, but needs to be validated: thus, in future work laboratory experiments and shop-floor tests have to 
be performed. Nevertheless, the proposed framework is general enough to be deployed with any of the available additive technologies discussed in section 2; thus, several, different tests can be performed.

\section{References}

1. ASTM: F2792-12a, Standard technology for additive manufacturing technologies. ASTM International, West Conschohocken (2012).

2. Frazier, W.E.: Metal Additive Manufacturing: A Review. Journal of Materials Engineering and Performance, 23(6), 1917-1928 (2014). doi: 10.1007/s11665-014-0958-z.

3. Ben Khedher, A., Henry, S., and Bouras, A.: Integration between MES and Product Lifecycle Management. In: Emerging Technologies \& Factory Automation (ETFA), 2011 IEEE 16th Conference on, 1-8. (2011). doi: 10.1109/etfa.2011.6058993.

4. D'Antonio, G., Sauza Bedolla, J., Chiabert, P., and Lombardi, F.: PLM-MES integration to support collaborative design. In: 20th International Conference on Engineering Design, ICED15. Milano (2015). doi:

5. Doubrovski, Z., Verlinden, J.C., and Geraedts , J.M.P.: Optimal Design for Additive Manufacturing: Opportunities and Challenges. In: 16th Design for Manufacturing and the Life Cycle Conference, 635-646. Washington, DC, USA (2011). doi: 10.1115/DETC201148131.

6. Mellor, S., Hao, L., and Zhang, D.: Additive manufacturing: A framework for implementation. International Journal of Production Economics, 149(0), 194-201 (2014). doi: 10.1016/j.ijpe.2013.07.008.

7. Rao, P., Liu, J., Roberson, D., Kong, Z.J., and Williams, C.: Online Real-time Quality Monitoring in Additive Manufacturing Processes using Heterogeneous Sensors. Journal of Manufacturing Science and Engineering, (2015). doi: 10.1115/1.4029823.

8. Incorporated, E.: Measurement Science Roadmap for Metal-Based Additive Manufacturing. National Institute of Standards and Technology, Columbia, Maryland, USA (2013).

9. Vayre, B., Vignat, F., and Villeneuve, F.: Metallic additive manufacturing: state-of-the-art review and prospects. Mechanics \& Industry 13(2), 89-96 (2012). doi: $10.1051 / \mathrm{meca} / 2012003$.

10. Markets, M.a.: Additive Manufacturing Market, By Application (Medical Devices, Automotives, \& Aerospace) and Technology (3D Printing, Laser Sintering, Stereolithography, Fused Deposition Modeling, Electron Beam Melting, \& Tissue Engineering) - Forecast (2012 - 2017). Markets and Markets, (2013).

11. Turner, B.N., Strong, R., and Gold, S.A.: A review of melt extrusion additive manufacturing processes: I. Process design and modeling. Rapid Prototyping Journal, 20(3), 192-204 (2014). doi: 10.1108/RPJ-01-2013-0012.

12. Laverne, F., Segonds, F., Anwer, N., and Le Coq, M.: Conception pour la fabrication additive: un état de l'art. In: AIP Primeca. La Plagne, France (2015). doi:

13. Gibson, I., Rosen, D.W., and Stucker, B.: Additive Manufacturing Technologies. Springer, New York (2010).

14. Ponche, R., Hascoet, J.Y., Kerbrat, O., and Mognol, P.: A new global approach to design for additive manufacturing. Virtual and Physical Prototyping, 7(2), 93-105 (2012). doi: 10.1080/17452759.2012.679499.

15. Huang, Y., Leu, M.C., Mazumder, J., and Donmez, A.: Additive Manufacturing: Current State, Future Potential, Gaps and Needs, and Recommendations. Journal of Manufacturing Science and Engineering, 137(1), 014001:1-10 (2015). doi: 10.1115/1.4028725. 
16. Ponche, R., Kerbrat, O., Mognol, P., and Hascoet, J.-Y.: A novel methodology of design for Additive Manufacturing applied to Additive Laser Manufacturing process. Robotics and $\begin{array}{lllll}\text { Computer-Integrated } & \text { Manufacturing, } & 30(4), & 389-398 & \text { (2014). doi: }\end{array}$ 10.1016/j.rcim.2013.12.001.

17. Rosen, D.W.: Computer-Aided Design for Additive Manufacturing of Cellular Structures. Computer-Aided Design and Applications, 4(5), 585-594 (2007). doi: 10.1080/16864360.2007.10738493.

18. Meyer, H., Fuchs, F., and Thiesl, K.: Manufacturing Execution Systems (MES): Optimal Design, Planning, and Deployment 1st ed. (2009).

19. Arica, E. and Powell, D.: A framework for ICT-enabled real-time production planning and control. Advances in Manufacturing, 2(2), 158-164 (2014). doi: 10.1007/s40436-014-00705.

20. Snatkin, A., Karjust, K., Majak, J., Aruväli, T., and Eiskop, T.: Real time production monitoring system in SME. Estonian Journal of Engineering, 19(4), $62-75$ (2013). doi: 10.3176/eng.2013.1.06.

21. Zhong, R.Y., Dai, Q.Y., Qu, T., Hu, G.J., and Huang, G.Q.: RFID-enabled real-time manufacturing execution system for mass-customization production. Robotics and Computer-Integrated Manufacturing, 29(2), 283-292 (2013).

22. Vijayaraghavan, V., Garg, A., Lam, J., Panda, B., and Mahapatra, S.S.: Process characterisation of 3D-printed FDM components using improved evolutionary computational approach. The International Journal of Advanced Manufacturing Technology, 1-13 (2014). doi: 10.1007/s00170-014-6679-5.

23. Byun, H.-S. and Lee, K.H.: Determination of the optimal build direction for different rapid prototyping processes using multi-criterion decision making. Robotics and ComputerIntegrated Manufacturing, 22(1), 69-80 (2006). doi: 10.1016/j.rcim.2005.03.001.

24. Sood, A.K., Equbal, A., Toppo, V., Ohdar, R.K., and Mahapatra, S.S.: An investigation on sliding wear of FDM built parts. CIRP Journal of Manufacturing Science and Technology, 5(1), 48-54 (2012). doi: 10.1016/j.cirpj.2011.08.003.

25. Sood, A.K., Ohdar, R.K., and Mahapatra, S.S.: Experimental investigation and empirical modelling of FDM process for compressive strength improvement. Journal of Advanced Research, 3(1), 81-90 (2012). doi: 10.1016/j.jare.2011.05.001.

26. Bukkapatnam, S. and Clark, B.: Dynamic Modeling and Monitoring of Contour Crafting An Extrusion-Based Layered Manufacturing Process. Journal of Manufacturing Science and Engineering, 129(1), 135-142 (2006). doi: 10.1115/1.2375137.

27. Faes, M., Abbeloos, W., Vogeler, F., Valkenaers, H., Coppens, K., Goedemé, T., and Ferraris, E.: Process Monitoring of Extrusion Based 3D Printing via Laser Scanning. In: 6th International Conference on Polymers and Moulds Innovations (PMI), 363-367. Guimaraes, Portugal (2014). doi: 10.13140/2.1.5175.0081.

28. Reutzel, E.W. and Nassar, A.R.: A survey of sensing and control systems for machine and process monitoring of directed-energy, metal-based additive manufacturing. Rapid Prototyping Journal, 21(2), 159-167 (2015). doi: 10.1108/RPJ-12-2014-0177.

29. Anwer, N., Ballu, A., and Mathieu, L.: The skin model, a comprehensive geometric model for engineering design. CIRP Annals - Manufacturing Technology, 62(1), 143-146 (2013).

30. Schleich, B., Anwer, N., Mathieu, L., and Wartzack, S.: Skin Model Shapes: A new paradigm shift for geometric variations modelling in mechanical engineering. ComputerAided Design, 50(0), 1-15 (2014). doi: 10.1016/j.cad.2014.01.001.

31. Huang, Q., Nouri, H., Xu, K., Chen, Y., Sosina, S., and Dasgupta, T.: Statistical predictive modeling and compensation of geometric deviations of three-dimensional printed products. Journal of Manufacturing Science and Engineering, 136(6), (2014). doi: 10.1115/1.4028510.

32. Tong, K., Joshi, S., and Lehtihet, A.: Error compensation for fused deposition modeling (fdm) machine by correcting slice files. Rapid Prototyping Journal, 14(1), (2008). 